\title{
А.А. Яшин \\ КОГНИТИВНАЯ РИГИДНОСТЬ КАК ФАКТОР НЕДОСТАТОЧНОЙ УСПЕШНОСТИ
}

\begin{abstract}
Аннотация. В статье рассматривается феномен когнитивной ригидности: биологические, социальные и иные причины её возникновения, развития. Делается обзор имеющихся исследований, анализ самого понятия "когнитивная ригидность" и терминов близких ему. Автор излагает идею наличия данного феномена при многих психических заболеваниях, приводит ряд фактов, доказывающих дезадаптивное влияние феномена на поведение человека, его успешность в профессиональной и любой другой срере. Доказывается необходимость создания специальных коррекционных программ для подростков, старших икольников и взрослых. Проведён теоретический анализ таких явлений, как общая психическая и когнитивная ригидность. Осуществлён анализ методической литературы и научных трудов российских и зарубежных авторов. Выдвигается идея возможного влияния средовых факторов на формирование когнитивной ригидности, которая в дальнейшем усложняет и снижает адаптацию человека в быстро меняющемся мире. Автором предполагается создание программы коррекции когнитивной ригидности у подростков и старших школьников с целью повышения у них мотивации к обучению, улучшения успеваемости.

Ключевые слова: психическая ригидность, установка, когнитивная ригидность, успешность, адаптивность, дезадаптивное поведение, нейронная пластичность, психическое заболевание, деятельность, мышление.

Review. In his article Yashin discusses the phenomenon of cognitive rigidity, particularly, biological, social and other causes of its origin and development. The researcher provides a reivew of available studies as well as performs the analysis of the concept of "cognitive rigidity" and associated terms. The author offers a hypothesis that this phenomenon is present in many mental illnesses and provides several facts proving disadaptive influence of the phenomenon on human behavior and his success in professional and any other sphere. The author has also emphasized the need for creating special intervention programs for teenagers, high school students and adults. Yashin has carried out the theoretical analysis of such phenomena as overall mental and cognitive rigidity. He also analyzes methodological literature and scientific researches of Russian and foreign authors and proposes that environmental factors may influence the development of cognitive ridigity which, at a later stage, complicates and reduces adaptation of human in a fast-paced world. The author suggests to develop the program of cognitive ridigity intervention for teenagers and high school students in order to boost their learning motivation and academic success.
\end{abstract}

Key words: neural plasticity, disadaptive behavior, adaptability, success, attitude, cognitive rigidity, mental rigidity, mental disease, activity, cogitation.

\section{Введение}

К проблеме когнитивной ригидности постоянно обращаются психологи самых разных научных школ и их направлений. Её изучение отражено в огромном количестве экспериментальных работ и теоретических интерпретациях, причём почти каждый исследователь даёт своё определение понятию "ригидность", хотя все дефиниции несут достаточно схожий смысл, несмотря на различия в теоретических подходах и терминологии. Под ригидностью понимается использование субъектом неадекватных для определённой конкретной ситуации стереотипных форм поведения, его неспособность изменять стратегию, которая могла быть успешной ранее, но сейчас потеряла свою актуальность.
Несмотря на уже имеющуюся литературу, которая посвящена данной теме, проблема ригидности настолько широка, сложна и актуальна, что интерес к ней не ослабевает. Появившиеся в последнее время методы исследований стали причиной очередного витка изучения этой темы и её разбора, как в теоретическом, так и экспериментальном русле. Значимость таких работ очевидна: изучение любых закономерностей ригидного поведения, тех причин, по которым оно возникает, вносит свой вклад в понимание сути явления, которое снижает уровень адаптации у здоровых людей, а у пациентов психиатрических клиник может быть одним из главных симптомов целого ряда заболеваний.

Когнитивная ригидность рассматривается различными теоретическими концепциями 


\section{Потенциал интеллекта}

(Л.С. Выготского, Р. Кэттелла, К. Левина, З. Фрейда, К. Гольдштейна, Г.В. Залевского и др.) и чаще всего трактуется как тугоподвижность мышления, жёсткость когнитивных схем, стереотипия.

При решении мыслительных задач ригидность проявляется в привязанности к рутинному способу действия (К. Гольдштейн), недостаточной вариабельности реакций (Х. Вернер), неспособности изменить установку (Р. Кеттэлл), конкретности мышления (Л.С. Выготский). В общем виде ригидность может быть определена как трудность в переключении на что-либо новое, неспособность изменять способ реагирования при новых условиях, некоторая сопротивляемость изменениям.

Ригидность - одна из базовых характеристик личности человека, влияющая на возникновение и проявление более частных личностных черт. В противоположность ей, гибкость является одним из условий, которое предопределяет возможность успешной адаптации к изменяющимся условиям внешней среды и нахождения человеком решений для широкого диапазона жизненных проблем, приводящих его к их благоприятному разрешению.

Ригидное реагирование как устойчивая личностная характеристика мешает формированию психического гомеостаза в ситуации изменения внешней среды. Это происходит за счёт фиксации человека на поведенческих стратегиях неэффективных в новых реалиях.

Ряд авторов [1; 2; 3] указывают на то, что между ригидностью и гибкостью имеется обратная корреляция, а значит, их можно рассматривать как полюса единого целого. Гибкость при оценке собственных личностных характеристик, деятельности и её результатов, умение переоценить под напором опыта систему своих ценностей, сложившуюся ранее, является одним из важнейших условий психической целостности, успешности и, в целом, психического здоровья человека.

Исследования [4] доказывают, что в обыденном сознании понятия "успех" и “успешность" достаточно дифференцированы. В понятии "успех" люди склонны чаще видеть объективно положительные результаты и жизни, и их конкретной активности, поведения. “Успешность” в большей степени отражает условия достижения успеха и те субъективные переживания, которые ощущает индивид. При этом для большинства людей в России главным условием достижения успеха являются внешние ресурсы. Значимость личностных характеристик либо уходит на второй план, либо вовсе нивелируется.

Существующие в обществе стереотипные взгляды на успешного человека, как индивида, который обладает лишь внешними ресурсами, а по своим личностным характеристикам не отличается от большинства других людей, препятствуя развитию когнитивной гибкости, усложняют адаптацию и ведут к снижению успешности.

В данной статье мы:

1) демонстрируем необходимость пересмотра существующих в обществе представлений с позиции "успешный человек = внешние ресурсы", на позицию "успешный человек = личностные характеристики";

2) доказываем существование отрицательной корреляции между когнитивной ригидностью и успешностью человека в его конкретной деятельности;

3) предлагаем рассмотреть когнитивную ригидность как одну из главных причин социальной дезадаптации и ключевой симптом большинства психических заболеваний.

\section{Понятие “когнитивная ригидность”}

Многие психологи, занимавшиеся изучением психической ригидности, независимо друг от друга, приходили к заключению, что эта проблема является одной из тех областей психологии, где исследователь оказывается на весьма непрочном фундаменте, постоянно сталкиваясь с сюрпризами и трудностями. Психическая ригидность - понятие, которому на данном этапе трудно, а может быть, даже невозможно дать одно определение, которое устроило бы абсолютно всех [2, с. 8].

Психическая ригидность (лат. rigidus - жёсткий, твёрдый) в психологии [5; 6] - неспособность и неготовность к перестройке намеченной субъектом схемы активности в условиях, объективно требующих её изменений. Психическая ригидность в медицине [6; 7] - психопатологическое состояние, характеризующееся недостаточной подвижностью психических процессов, нарушениями переключаемости мышления и речи, инертностью установок, что значительно затрудняет адаптацию больных к изменяющимся условиям внешней среды.

Проявляемый субъектом уровень психической ригидности обуславливается взаимодействием характера среды (степень опасности условий, уровень сложности задачи, привлекательность цели, монотонность и аритмичность стимуляции и т.д.) с лично-индивидуальными характеристиками индивида [8; 9; 10 и др.].

Традиционно выделяют мотивационную, аффективную и когнитивную ригидность.

Аффективная ригидность (ригидность аффекта) - неспособность изменить структуру аффективных проявлений, которая может проявляться в 


\section{Психология и психотехника 11(86) • 2015}

неизменности эмоциональной значимости объекта, фиксации на однообразных объектах, замедленном эмоциональном научении и т.д. Данный вид ригидности отражается в однообразности аффективных откликов на изменившиеся предметы эмоций.

Мотивационная ригидность проявляется в тугоподвижной перестройке системы мотивов в обстоятельствах, требующих от субъекта гибкости и изменения характера поведения. Индивид, обладающий мотивационной ригидностью, не способен изменить систему внутренних причин, подталкивающих его к деятельности.

Аффективная и мотивационная ригидность проявляются также в склонности к образованию сверхценных идей, в эгоцентризме и повышенной самооценке, в узости интересов, упрямстве, застреваемости на одних и тех же мыслях и эмоциях [5].

Когнитивная ригидность - неспособность изменить представления об окружающей среде в соответствии с действительными изменениями этой среды. Когнитивная ригидность может проявляться, например, в перцептивной ригидности - нарушении способности адекватно воспринимать объект в изменившейся ситуации.

В психологии фиксирование установки (эффект предшествования, прайминг) является эффектом имплицитной (скрытой) памяти. При нём реакция, возникающая на действие определённого стимула, влияет на реакцию, которая возникает в ответ на последующие стимулы, что может осознаваться или не осознаваться человеком [8; 11; 12].

По сравнению с ситуацией, когда фиксирование установки полностью отсутствует, негативное фиксирование установки приводит к замедлению обработки воздействия стимула, а позитивное - к её ускорению [13].

Другой пример когнитивной ригидности функциональная фиксированность.

Суть этого психологического феномена, который был открыт и описан Карлом Дункером [11], заключается в том, что, начав использовать какойлибо предмет в одном качестве, субъекту сложно переключиться на использование того же предмета в ином качестве в этой же текущей ситуации.

Когнитивная ригидность проявляется в трудностях перестройки восприятия и представлений в ситуации, которая уже изменилась.

В сознании большинства, проявления ригидности оцениваются негативно. Такая оценка не зависит от того проявляется ли ригидность как личностная особенность конкретного человека, или она возникает лишь в определённой ситуации. В целом ряде случаев этим термином определяют способность человека выполнять однотипную, монотонную работу (операторы автоматических линий, диспетчеры и т.д.) [1; $14 ; 15 ; 16]$.

Когнитивная ригидность является одной из главных причин деструктивности не только индивидуального, но и группового поведения. Её влиянию подвержены группы самых разных размеров. Например, предубеждения, социальные стереотипы, связанные с половыми, межконфессиональными, межнациональными и другими противоречиями становятся причиной многих конфликтов, когда они обретают устойчивость и глобальный характер, обусловленный ригидностью массового сознания [17; 18].

Многие хотели бы быть успешными в своей деятельности, ставить и достигать цели [4]. Очевидно, что для этого необходимо использовать ресурсы, которые условно можно разделить на две большие группы: внешние и внутренние.

К первым можно отнести всё, что приобретается за деньги, ко вторым - то, что купить нельзя, а можно лишь в определённых границах сформировать: личностные характеристики. Безусловно, главный критерий успешности - чувство удовлетворенности своей жизнью [18].

В.Д. Шадриков разносторонне рассматривает свойства психических (познавательных) процессов как характеристики продуктивности, отражающие их связи с эффективностью внешней деятельности (по параметрам производительности, качества и надёжности) [19]. С позиции системной структуры деятельности Б.Н. Рыжов определяет продуктивность психической деятельности как совокупность трёх параметров: сложности образуемых системных связей, объёма перерабатываемой информации и темпа деятельности [20]. Очевидно, что эти параметры характеризуют мышление, которое становится центральным звеном в регуляции не только познавательных процессов, но и всей психической деятельности.

В обычных житейских и производственных ситуациях проявляются наиболее характерные для человека стратегии преодоления проблемы, привычные способы мышления. Доминирующие способы мышления являются устойчивой характеристикой личности [21].

Если же человек реагирует на проблемную ситуацию, лишь опираясь на свой предыдущий опыт (в т.ч. свои взгляды и убеждения), без подробного анализа текущей ситуации, то риск ошибки резко возрастает. Именно такое поведение и стиль мышления, ему предшествующий, мы будем считать ригидным.

Современные схемы когнитивного поведения считают процесс восприятия сигналов из внешней среды сопоставлением сенсорной информации с не- 


\section{Потенциал интеллекта}

которым ранее хранящимся в памяти образом или знанием об объекте [22]. Когда объект появляется во внимании второй раз, его образ может либо совпасть, либо не совпасть с уже сформированным. Совпадение делает когнитивную деятельность легче, а несовпадение новой информации с ранее оформившейся установкой создаёт конфликт, в результате которого появляется нисходящее влияние со стороны ранее сформированного знания на процессы повторного, нового опознания стимула. Такое влияние приводит к искажениям повторного восприятия [12].

В своих работах Р. Кэттелл [23] показал особый склад личностей, обладающих высокой когнитивной ригидностью. Они не очень самостоятельны, но точны и исполнительны. Напротив, люди, обладающие когнитивной гибкостью, сообразительны, быстро схватывают новое, но редко терпят ограничения свободы.

Было выявлено, что степень выраженности когнитивной ригидности зависит от целого ряда факторов, главными их которых являются индивидуальные особенности личности, уровень мотивации, степень сложности предлагаемых когнитивных задач [8; 9; 10; 24; 25]. Проблема роли индивидуальных личностных характеристик в формировании когнитивной ригидности не решена и требует дальнейшего изучения.

Любопытная зависимость была выявлена между когнитивной ригидностью и уровнем мотивации $[10 ; 22 ; 24 ; 26]$. Исследования показали, что мотивация выполнять задачи правильно, с одной стороны, благоприятно сказывается на результате когнитивной деятельности, но с другой - приводит к нарастанию ригидности, что, в свою очередь, ухудшает результат тестов.

Имеется чёткая зависимость между выраженностью когнитивной ригидности, сложностью предлагаемых задач, объёмом выполняемой когнитивной деятельности. Чем сложнее последняя, тем выше инертность формирующихся неосознанных установок $[27 ; 28]$.

Г. Джаспар впервые обнаружил в глубинных структурах мозга (гиппокамп и др.), так называемые нейроны новизны и тождества (или внимания) - нервные клетки, реагирующие на первые предъявления стимулов, их новизну. Фоновая импульсация этих клеток увеличивается при воздействии новых стимулов разной модальности. По мере того, как эти стимулы будут повторяться, ответ нейронов новизны избирательно подавляется так, что дополнительная активация в нём исчезает и сохраняется лишь фоновая активность [29, с. 118-119].

Н.П.Бехтеревой с сотрудниками была продемонстрирована работа нейронных популяций, реагирующих только на ошибочную реализацию деятельности [30; 31]. Эти ансамбли нейронов активизируются не при выполнении какой-то конкретной деятельности, а только тогда, когда существует ошибка с изначально составленным планом, полученной установкой.

Изначально термином “ригидность" пользовались в медицине и физиологии для описания состояния мышц, долгое время находящихся в повышенном тонусе (например, вследствие повреждения моста мозга, развития менингита и т.д.), но затем это понятие перекочевало в психиатрию. Далее мы рассмотрим ряд психических и неврологических заболеваний, при которых когнитивная ригидность проявляется особенно часто и, фактически, является не отдельным феноменом, а симптомом в структуре определённой нозологической единицы.

Психическое заболевание можно рассматривать как крайнюю степень дезадаптированности, когда под угрозой находится само существование индивида. Очевидно, что многие психические заболевания, являясь прогредиентными, становятся причиной нарушения всех высших психических функций, особенно при тяжёлых степенях болезни. Когнитивную ригидность тут сложно дифференцировать от нарушений внимания, восприятия, памяти [32]. Вместе с тем, вопрос наличия или отсутствия когнитивной ригидности становится особенно значимым при психических расстройствах, т.к. во-первых, она связана с наличием у пациента критичности к качеству своего психического отражения, а во-вторых, с отношением человека к своему лечению, психотерапии и дальнейшей социальной реабилитации.

Общая психическая ригидность в клинической психологии - это расстройство психики, при котором снижены подвижность, переключаемость и приспособляемость психических процессов к меняющейся ситуации [33].

Более широким понятием "инертное мышление” обычно характеризуют группу синдромов, основным признаком которых является недостаточность подвижности психических процессов. К подобным нарушениям относят вязкое мышление, стереотипное мышление, персеверативное мышление [2; 34].

Инертное мышление может быть выявлено при самых разных заболеваниях. Особо часто оно имеется как у людей, страдающих шизофренией, так и у пациентов, имеющих грубую органическую патологию головного мозга. Следовательно, одинаковые патогенетические механизмы способны формироваться на фоне и функциональных, и органо-деструктивных изменений. 


\section{Психология и психотехника 11(86) • 2015}

Кратко рассмотрим основные варианты проявления инертности мышления в структуре определённых психических заболеваний и оценим их роль в формировании когнитивной ригидности.

Вязкое мышление часто сопровождает формы слабоумия, вызванные эпилепсией [35; 36]. Человек с такого рода инертным мышлением обстоятелен, склонен к детализации, не умеет отделять основное от второстепенного, тугоподвижен, "топчется” на месте, не может выйти за пределы определённых взглядов и переключиться на что-то новое. Инертность модуса деятельности больных эпилепсией особенно чётко проявляет себя при выполнении заданий, где необходимо переключение с одной задачи на другую. В мышлении больного эпилепсией преобладает конкретность. Такой тип мышления обязательно предполагает и когнитивную ригидность, недостаточную лабильность.

Под персеверативным мышлением рассматривают склонность к застреванию в сознании больного каких-либо мыслей, представлений, образов, фраз, вне зависимости от изменения ситуации и нарушения цели деятельности [2].

Часто такой тип мышления проявляется при грубейших органических патологиях головного мозга (церебральный атеросклероз, старческое слабоумие, олигофрения, болезнь Альцгеймера, Пика и др.). Особенно чётко он выявляется, когда локально нарушены лобные доли [34; 35; 37; 38].

Если одновременно поражён речевоспринимающий анализатор (например, при сенсорно-моторной афазии), то такому больному крайне тяжело заметить собственные персеверации [34].

Если психическую ригидность рассматривать с эволюционной точки зрения, то, очевидно, что, вопервых, она проявляется через многообразие фиксированных форм поведения, многие из которых у человека имеют древние филогенетические корни. Основанием для такого заявления служит целый ряд фактов [2, с. 188]. О роли семейных отношений, стиле воспитания и особенностях личности родителей в формировании ригидных черт характера у ребёнка сообщается в целом ряде исследований [39, с. 191].

Система образования может приводить к повышению гибкости, динамичности, вариативности системы отношений, установок, позиций человека, снижению его психической ригидности, но эффект её влияния не гарантирован и зависит от ряда факторов, главным из которых будет являться ориентированность системы образования на индивидуально-психологические особенности ребёнка.

В идеале, образовательная среда должна в первую очередь влиять на уровень сознательной саморегуляции личности, который отражает "уста- новочная ригидность" - осознанное принятие или непринятие нового, необходимости перемен в окружающей действительности и самой личности. Можно предполагать, что качественное образование способно привести к снижению ригидности в перцептивно-когнитивной сфере человека, но этот вывод подтверждается при сравнении более отдалённых друг от друга уровней образования [40, с. 193].

Ряд авторов считает, что человек способен удовлетворять определённые потребности, используя готовые схемы и без участия мышления как такового. Например, Г.А. Нижарадзе в своей диссертации пишет следующее: «В психологической литературе очень часто «психологию решения задач» рассматривают отдельно от «психологии мышления». И это совершенно правильно, так как решение задачи, вроде бы чисто интеллектуальной, во многих случаях может быть достигнуто и без помощи мышления в собственном смысле. Существеннейшим свойством мышления является проникновение в суть проблемы, вынесение на передний план её скрытого ядра. Этот процесс принято называть «постижением» или «инсайтем». Существует определенный класс задач, решение которых возможно только лишь с помощью инсайта. Однако наряду с последними есть и другие задачи, которые могут быть решены и иными способами, например, с помощью фиксированной схемы или метода проб и ошибок» [24]. Соглашаясь во многом с автором, подчеркнём, что те задачи, которые не требуют участия активного мышления, фактически становятся в деятельности лишь операциями, для выполнения которых высокий уровень ригидности может послужить хорошую службу. Так, мотивационная ригидность легко становится волей к победе, а аффективная ригидность превращается в такую черту человека, как храбрость. Вместе с тем, очевидно, что там, где нужна воля к победе и храбрость, особенно важно мышление, и именно поэтому мы уделяем повышенное внимание когнитивной ригидности.

Изучение представлений об успешности, проведённое Н.В.Лейфрид на разновозрастной выборке, выявило, что образ реального успешного человека включает в себя материальную обеспеченность, семью, карьерный рост, достижения поставленных целей, престижную работу, высокий социальный статус, статус руководителя и т.д. [4]. Понятно, что всё вышеперечисленное требует от человека способности ставить цели и достигать их. В свою очередь, планирование, целенаправленная деятельность и текущие препятствия выдвигают перед нами те задачи, которые часто невозможно решить одним упорством. Они требуют активной работы мышления и когнитивной гибкости. 


\section{Потенциал интеллекта}

И если человек обладает ригидным мышлением, имеет акцентуацию характера, которая может рассматриваться как один из вариантов проявления ригидности, то затруднена не только его самореализация, но и деятельность, направленная на удовлетворение базовых биологических потребностей.

Говоря о когнитивной ригидности, как процессе, снижающем возможности адаптации и самореализации человека, мы, в первую очередь, апеллируем к понятию когнитивных установок, которые осуществляют регулирующую и координирующую функции когнитивной деятельности. Чаще представленные на неосознанном уровне, они облегчают процесс обработки информации тех стимулов, в результате действия которых сформировались ранее, что существенно улучшает их опознание. Но установки могут порождать более или менее выраженную инертность в когнитивной и мыслительной деятельности.

Для успешного когнитивного процесса необходим определённый оптимальный уровень гибкости установки. Этот уровень, с одной стороны, должен давать возможность установке быть достаточно устойчивой, но с другой, она должна быть способна в случае необходимости угаснуть и дать сформироваться новой, которая будет более адекватна изменившейся ситуации и текущим действующим стимулам. Очевидно, что должно быть оптимальное сочетание двух, на первый взгляд, противоположных свойств формируемых установок (как на осознанном, так и на неосознанном уровне). В постоянно меняющейся окружающей среде успешная когнитивная деятельность человека возможна только при таком балансе. В противном случае, установки не будут эффективно выполнять свои регулирующие и координирующие функции на уровне целостных когнитивных процессов, в частности, процесса опознания и оценки стимулов внешней среды.

\section{Влияние психологических черт родителей и модели воспитания на психическое развитие ребёнка}

Очевидно, что огромное влияние на психическое развитие человека оказывают родители. Нарушения детско-родительских отношений приводят к формированию у ребёнка различных психологических проблем и комплексов, которые могут сохраняться до конца жизни и негативным образом влиять на адаптацию человека.

В психологической и педагогической литературе можно найти целый ряд работ, посвящённых изучению типов отношений родителей к детям и их влияния на развитие психологических характе- ристик личности, характерологических особенностей и поведения детей [41; 42; 43 и др.].

В этих работах описываются качества отца и матери, которые способствуют формированию устойчивой и неустойчивой привязанности ребёнка; определяются параметры «оптимального родителя» или «достаточно хорошего родителя», подвергаются обсуждению различные стили родительского поведения.

В России и СССР детско-родительские взаимоотношения изучались В.В. Столиным, А.С. Спиваковской, А.И. Захаровым и др. [42;43;44; 45 и др.].

Российскими психологами была предложена всеобъемлющая классификация моделей семейного воспитания детей и подростков, имеющих акцентуации характера и психопатии, а также устанавливается, возникновению какой аномалии развития способствует тот или иной тип родительского отношения [46; 47].

Из указанных исследований видно, что к возникновению у ребёнка различных психопатологий приводит сочетания неоднородных причин, которые находятся в различных сочетаниях друг с другом, с преобладанием того или иного вида дефицитарности и психогенного влияния. Особое внимание обращает на себя роль семейного фактора и стиля семейного воспитания.

Из обзора научных исследований следует, что одним из наиболее известный механизмом образования характерологических черт у детей, отвечающих за их социальную компетентность и самоконтроль, является интериоризация тех навыков контроля и средств, которые используются родителями. В этом случае разумный контроль предусматривает объединение эмоционального принятия с достаточно значительным уровнем требовательности к ребёнку. Очевидно, что любые запросы и требования к детям должны быть максимально чётки, логичны, последовательны в предъявлении детям. Ребёнок, выросший при таком отношении к нему родителей, легко социализируется, адаптируется к обучению в школе. Он свободен, доброжелателен, активен и эмпатичен.

Стиль взаимодействия с детьми повторяет сам себя и в значительной степени определяется традициями семьи. Родители повторяют ту модель воспитания, которую они видели в своём детстве. Черты характера мамы и папы будут являться важнейшими детерминантами схемы взаимодействия с ребёнком, сложившейся в семье. Например, А. Адлер одним из первых очертил тип тревожной матери, налаживающей со своим ребёнком некий симбиоз, следящей и максимально оберегающей его, тем самым блокирующей инициативность и само- 


\section{Психология и психотехника 11(86) • 2015}

стоятельность ребёнка, повышающей его общую и когнитивную ригидность [48].

По результатам наблюдений и экспериментально-психологических исследований пациентов А.И. Захаров [42; 43] формирует список личностных изменений у родителей, большая часть которых относится к сфере их «я». Эти изменения незначительны и не приводят к серьёзным нарушениям социализации, деструкциям и антиобщественным действиям. У родителей имеется серия личностных изменений, которые возможно систематизировать следующим образом.

«Слабость личности» - обострённая чувствительность к критике, страх ответственности за принятый решения, повышенная фиксированность на собственных переживаниях, недоверчивость, подозрительность.

«Ригидность личности» - гиперответственность, чрезмерное чувство долга, обязательства, негибкость, тугоподвижность мышления, консерватизм, сложности в том, чтобы принимать и играть различные социальные роли.

«Закрытость личности» - сниженная контактность, коммуникабельность, эмоциональная отзывчивость, удержание себя в проявлении чувств любви и нежности, заглушение внешних выражений переживаний, реакция самозащиты на большинство стрессовых ситуаций.

«Конфликтность личности» - ранимость, недоверие к людям, постоянное ощущение недовольства поведением других, склочность, скандальность, брюзжание, негативизм, раздражимость.

В работах А.И. Захарова [42; 43] рассматриваются типичные личностные характеристики родителей, чьи дети страдают неврозами. В первую очередь изучались мамы. Результаты психологических исследований показывают, что для мам детей с неврозами характерна чрезмерная чувствительность, сензитивность, тревожность, низкая самооценка, неуверенность в своих силах. Кроме того они отличаются повышенной пунктуальностью, педантичностью, принципиальностью, ригидностью мышления, морализаторством, склонностью к образованию сверх ценных идей, отсутствием толерантности, повышенной конфликтностью в межличностных отношениях, низкой способностью к эмпатии, неспособностью выражать свои чувства. Анализ результатов MМРI отцов таких детей показал, что они часто мягки, пассивны, с минорным фоном настроения. Следствием сочетания подобных личностных характеристик матери и отца становится искаженный тип семьи, где мама чрезмерно «мужественна» - предъявляет жёсткие требования, категорична и не эмпатична, а отец «женствен» - чувствительный, ранимый, утративший контроль над управлением ситуацией. Понятно, что родители с такими психологическими характеристиками предлагают своим детям неточные эталоны для идентификации и овладения социальных стереотипов поведения. И мать и отец сами несут похожую структуру фрустрированых потребностей. У них самих не удовлетворяется потребность в близости, принятии. Они сами стремятся к независимости и, одновременно, имеют страх перед изменениями, живут с ощущением внутреннего конфликта, недовольства собой, дискомфорта. Вместе с тем, психологические защиты, искаженные способы самоутверждения не дают родителям возможность понять, что происходит, принять себя, найти адекватное способы разрешения собственных внутренних противоречий. Дети в таких семьях играют роль «козлов отпущения», которые перенимают себе проекции психологических конфликтов родителей, а их неврозы становятся клиническим отражением психологических проблем значимых взрослых [42; 43].

А.Я. Варга [49] находит ряд общих психологических проблем у родителей, чьи дети больны ночным энурезом. В её исследованиях чётко продемонстрировано, как симптом невроза у ребёнка необходим тем родителям, которые испытывают сложности в сфере личных интимных взаимоотношений (1985).

Значительно более серьёзные нарушения характерологического плана выявляются у тех родителей, чьи дети больны шизофренией [50]. Мать таких детей выявляется по двум типичным установкам: 1) Она открыто отвергает ребёнка, но, одновременно, использует идеальный инструментальный контроль. Безразличие может граничить с садистским настроением; 2) Скрытое отклонение, при котором её явно избыточное опекание ребёнка становится вариантом доминирования и паразитарной жизни при существующих эгоистических и инфантильных установках. Отцы в таких исследованиях определялись как слабые, пассивно-равнодушные, самоустраняющиеся от решения семейных вопросов. Взаимодействие в семьях с больным шизофренией ребёнком выстраивается по принципу «двойной связи». Она определяется двойственностью, иррациональностью и противоречивостью тех мотивационных тенденций, к которым обращаются отец и мать.

Патологическая выраженность подобных личностных черт родителей создаёт особую модель их взаимодействия с ребёнком. Взрослые упорно не видят у себя тех же особенностей, на малейшее проявление которых у ребёнка они так аффективно- 


\section{Потенциал интеллекта}

болезненно реагируют и старательно искореняют. Родители бессознательно переносят свои проблемы на детей, а после реагируют на проявления этих проблем как на свои собственные. Желание родителей сделать из своего сына или дочери самого лучшего человека, по сути, является попыткой компенсировать свою собственную заниженную самооценку. Вместе с тем бессознательный перенос внутренних проблем родителей на ребёнка не определяет модель взаимодействия: в одной ситуации родители будут эмоционально отвергать того ребёнка, который не соответствует их представлению об идеальном ребёнке; в другой ситуации использовать по отношению к ребёнку гиперопеку или гиперпротекцию [51]. Весьма сильно обостряется негативное отношение к подростку, особенно в тех семьях, где есть второй маленький ребёнок: тут часто происходит переоценка достоинств младшего, на фоне которых реальные и вымышленные минусы подростка будут определяться родителями как непереносимые. Эмоциональная холодность и неприятие особо тяжело для обеих сторон в тех семьях, где мать постоянно боится того, что её ребёнок будет обладать психологическими чертами отца. Часто это неполные семьи, семьи, где отец страдает алкоголизмом. Отвержение матерью своего ребёнка тут может скрываться за гиперпротекцией.

Список таких патологически заострённых личностных характеристик родителей был получен и по другим психическим заболеваниям, которыми страдают дети.

Существующие исследования [51; 52; 53 и др.] показывают положительную корреляцию не только между личностно-психологическими характеристиками родителей и особенностями психического развития их детей. Ряд работ доказывают типичное влияние определённых моделей воспитания, которые формируются в семьях, где личностнопсихологические характеристики участников воспитательного процесса могут быть и диаметрально противоположными.

В современной литературе по психологии имеется ряд работ, направленных на изучение взаимосвязи различных характеристик личности ребёнка с особенностями его мышления [54]. С.Л. Рубинштейн указывал: «Чтобы приблизиться к мышлению в его конкретной реальности, нужно как бы выйти в новое содержание, рассмотреть мышление в личностном плане, как конкретную познавательную деятельность человека в её личностной мотивации» [55, с. 139]. Согласно взгляду Ж. Пиаже, мысль есть интернализированное действие. Сначала индивид совершает очередное действие, затем, в процессе мышления, тот же поступок он совершает в уме, и таким образом мысль становится интернализированным действием [57]. Л.С. Выготский писал о том, что нельзя понять мышление, особенно его развитие у ребёнка, вне связи с эмоциями [56, с. 272].

Мышление - это обобщённое отражение объективной действительности в её закономерных, наиболее существенных связях и отношениях. Иными словами, мышление есть психический процесс познания, связанный с открытием субъективно нового знания, с решением задач, с творческим преобразованием действительности [5; 33]. Развитие мышления происходит от младенчества до самой зрелости. В процессе этого пути случается переход от наглядно-действенного мышления (начальный этап) к словесно-логическому мышлению (наивысший этап).

Как правило, качественное изменение мышления происходит в подростковом периоде. В этом возрастном этапе понятийное мышление начинает проявлять себя значительно чаще, чем в младшем школьном возрасте. Вместе с тем, у подростка, теоретическое рефлексивное мышление также продолжает развиваться [54; 57 и др.]. Полученные в младшем школьном возрасте операции становятся формально-логическими. Подросток приобретает способность использовать гипотетико-дедуктивный способ рассуждения: на базе единых закономерностей он выстраивает гипотезы и проверяет их истинность, абстрагируясь от конкретных, наглядных раздражителей, рассуждает при помощи речи, решает интеллектуальные задачи. При дальнейшем развитии способность к системному поиску решений будет развиваться в ещё большей степени. При столкновении с задачами нового типа, всё в большей и большей степени будут применяться различные подходы к поиску их решений, проверяться логическая эффективность каждого такого подхода.

Семья будет оказывать значительное влияние и на развитие мышления подростка. Так происходит из-за того, что она с самых первых этапов развития фактически ориентирует сознание, эмоции, волю ребёнка. Очень многое зависит от того, какое место занимает в семье ребёнок, каков семейный уклад, традиции, тип семейного воспитания. Именно под руководством мамы и папы дети получают свой первый жизненный опыт, простейшие представления о том в мире, в котором живут, модели поведения в обществе.

Интеллектуальное развитие подростков в значительной степени зависит от того влияния, которое ежедневно оказывается на него родителями, самой атмосферой интеллектуальной жизни семьи $[47 ; 51 ; 58 ; 59]$. Оно зависит и от того, на- 


\section{Психология и психотехника 11(86) • 2015}

сколько целенаправленна деятельность взрослых по формированию и удовлетворению познавательных потребностей подростков, развитию их представлений о мире и о себе, расширению кругозора. Уровень развития интеллекта подростка определяется и тем, как взрослые удовлетворяют в семье его духовные потребности, как организуют деятельность подростка, какую речевую среду создают в семье и др. Семья способна развивать у подростка способность выстраивать свои рассуждения логически, формировать различные понятия в бытовом и учебном плане.

Вместе с тем, влияние личностно-психологических характеристик взрослых и стиля семейного воспитания на развитие у ребёнка высших психических функций, их патологии (в т.ч. ригидность мышления) требует дополнительных исследований. Если подобное влияние будет обнаружено, автоматически встанет вопрос о возможности проведения коррекционной работы с родителями и детьми. Мишенью психологической коррекции могла бы стать когнитивная ригидность, которая очевидно препятствует взрослым в работе по формированию мотивации к обучению, снижает интеллектуальные возможности ребёнка.

\section{Заключение}

Современный мир меняется с огромной скоростью и, очевидно, что с каждым днём эта скорость будет возрастать. Автоматизация производственных процессов уменьшает количество рабочих мест. Всё больше видов работ можно выполняться дистанционно, и всё больше количество человек, проживающих в разных странах мира, будут претендовать на выполнение вашей работы. Люди становятся гораздо мобильнее, и трудовая миграция растёт в арифметической прогрессии. Один из способов быть успешным в таких условиях - изменяться с той же скоростью, что и мир.

Обычно, уже к 35-40 годам люди теряют свою способность к развитию и быстрой адаптации. Интеллектуальные нагрузки, которые связаны с необходимостью изучать что-либо новое становятся непосильными и утомительными, а новая информация малопонятной. Особым образом эта проблема актуальна для представителей среднего возраста, от успешности которых зависит не только их собственное процветание, но и процветание их детей.

Появление у человека когнитивной ригидности зависит от ряда факторов. Она часто возникает на фоне возрастных изменений или является одним из симптомов психического заболевания, которое, в свою очередь, может быть обусловлено биологическими и социальными причинами. Одним из таких социальных факторов, влияющих не только на формирование личностно-психологических черт человека, но и особенностей его когнитивной сферы, является семья.

Можно выделить ряд факторов семейного воспитания, влияющих на развитие интеллекта ребёнка, гибкости его мышления. Среди них будет позиция родителей по отношению к развитию и способы воздействия на ребёнка, отношение семьи к развитию интеллекта ребёнка, стили детско-родительских отношений, стиль контроля и руководства ребёнком, состав семьи и отношение внутри неё и др.

Сейчас практически все психологи согласны с той точкой зрения, что строгий контроль, психологическое подавление и иные формы грубого авторитарного давления препятствую нормальному психическому развитию ребёнка, в т.ч. развитию у него высших психических функций. Исследования Д. Боумрина, В.С. Шипмана и Р.Д. Хеса [60] доказали, что у детей, чьи родители предпочитают во взаимодействии с ребёнком лишь приказывать и контролировать, развивается конформизм, податливость, зависимое поведение, снижается уровень познавательной активности.

Напротив, инструктивный стиль, который предполагает, что ребёнку даётся больше информации с обоснованием требований, развивает инициативу и творческое мышление. При таком стиле взаимодействия родители общаясь с ребёнком, объясняют свои требования и смотрят на него как на равноправного партнёра, но, пока, уступающего им по опытности и теоретической подготовленности к жизни. Такие взаимоотношения мотивируют детей к самостоятельности в поиске и принятии решений, дают возможность выбора в тех ситуациях, к которым ребёнок уже достаточно подготовлен. Именно такой стиль взаимодействия с ребёнком выявлен в тех семьях, где дети имеют высокий уровень интеллектуального развития. Конечно, давая ребёнку дозированное право на свободу выбора, в отдельных ситуациях родители могут столкнуться с конфликтом, на который готов пойти ребёнок, отстаивающий свою личную точку зрения. С другой стороны, при достаточной обоснованности требований, ребёнок будет действовать более осознанно, оперативно и добровольно. У детей, растущих в таких семьях, формируется ориентация не на внешний, а на внутренний контроль, который необходим для развития самых различных задатков.

Очевидно, что дополнительные исследования психологов дополнят уже имеющуюся информацию о появлении и развитии когнитивной ригид- 
ности, коррекция которой, возможно, поможет повысить успешность человека, его социализацию и адаптацию. Эта коррекционная работа может проводиться не только с взрослым человеком, но и с родителями детей и подростков. Семья, в которой одобряются познавательные и творческие устремления детей, в которой тратятся существенные усилия для активного развития их способностей, где маленький человек воспринимается как самоценная личность со всеми своими индивидуальными и возрастными особенностями, а контроль и руководство за детским развитием базируется на принципах уважения и ответственности, имеет все шансы вырастить способного, интересного, творческого человека открытого для познания себя и окружающего мира.

\section{Список литературы:}

1. Гордыня Н.Д. Исследование ригидности-гибкости познавательного контроля и импульсивности-рефлективности у студентов-авиадиспетчеров // Молодой ученый. 2013. № 5. С. 634-638.

2. Залевский Г.В. Психическая ригидность в норме и патологии. Томск: Изд-во Томского университета, 1993. 272 с.

3. Х Холодная М.А. Психология интеллекта: парадоксы исследования. 2-ое изд., перераб. и доп. СПб.: Питер, 2002.272 с.

4. Лейфрид Н.В. Ответственность как личностная детерминанта представлений об успешном человеке: Дис. ... канд. психол. наук. Краснодар, 2006. 220 с.

5. Зинченко В.П., Мещерякова Б.Г. Психологический словарь. М.: Педагогика-пресс, 1996. 367 с.

6. Творогов Н.Д. Клиническая психология. М.: ПЕР СЭ, 2007. 416 с.

7. Блейхер В.М., Крук И.В., Боков С.Н. Клиническая патопсихология. Воронеж: НПО «МОДЭК», 2002.512 с.

8. Норакидзе В.Г. Темперамент личности и фиксированная установка // Экспериментальные исследования по психологии установки. Т. 1. Тбилиси: Изд-во АН ГССР, 1958. 348 с.

9. Cowen E.L. The influence of varying degrees of psychological stress on problem-solving rigidity // J. of Abn. and Soc. Psychol. 1952. N. 47. P. $512-529$.

10. Luchins A.S., Luchins E.H. Wertheimer's seminars revisited. Problem-solving and thinking. V. 3. Albany, 1970. 439 p.

11. Дункер К. Психология продуктивного (творческого) мышления // Психология мышления: Сб. переводов с нем. и англ. / Под ред. А.М. Матюшкина. М.: Прогресс, 1965. С. 199-221.

12. Узнадзе Д.Н. Экспериментальные основы психологии установки // Экспериментальные исследования по психологии установки / Ред. А.С. Прангишвили, 3.И. Ходжава. Тбилиси: Изд-во Грузинской АН, 1958. С. 5-126.

13. Kolb \& Whishaw: Fundamentals of Human Neuropsychology. 2003. P. 453-454, 457.

14. Бурмистрова Е.В., Максутова Н.Г. Когнитивные и личностные особенности операторов связи служб экстренного реагирования // Материалы I Международного форума «Психологическая безопасность, устойчивость, психотравма» (СПб., 57 июня 2006 г.) / Под ред. И.А. Баевой, Ш. Ионеску, Л.А. Регуш, С.А. Чернышевой. СПб.: Книжный дом, 2006. 214 с.

15. Иванова Е.М. Психология профессиональной деятельности. М.: Когито-центр, 2011. 336 с.

16. Максутова Н.Г. Проблемы подготовки операторов связи информационных центров служб спасения // Материалы научно-практической конференции «Проблемы психологии XXI века глазами молодых учёных». М.: ЭЛЛАРАДА, 2002. C. 85-87.

17. Волков Е.Н. Основные модели контроля сознания (реформирования мышления) // Журнал практического психолога. 1996. № 5.

18. Брушлинский А.В. Субъект: мышление, учение, воображение. М.: МПСИ; Воронеж: МОДЭК, 2003. 398 с.

19. Шадриков В.Д. Психология деятельности и способности человека. М.: Логос, 1996. 320 с. С. 198-222.

20. Рыжов Б.Н. Системная психология. Методология и методы психологического исследования. М.: МГПУ, 1999.277 с. C. 139-175.

21. Романова Е.С., Решетина С.Ю. Профессиональная ориентация с позиций концепции самодиагностики // Прикладная психология. 2001. № 3. С. 19-40.

22. Костандов Э.А. Психофизиология сознания и бессознательного. СПб.: Питер, 2004. 176 с.

23. Cattell R.B. The scientific analysis of personality. Baltimore Praeger, 1965.

24. Нижарадзе Г.А. Влияние мотивационных факторов на ригидное поведение: Дис. ... канд. психол. наук. Тбилиси, 1984. 132 с.

25. Нижарадзе Г.А. О двух типах ригидности при решении интеллектуальных задач // Вопросы психологии. 1987. № 3. C. $142-145$.

26. Курова Н.С., Черемушкин Е.А., Ашкинази М.Л. Когерентность ЭЭГ при действии неосознаваемой зрительной установки в условиях повышенной мотивации испытуемых // Журнал высшей нервной деятельности им. И.П. Павлова. 2003. № 6. С. 705-711.

27. Костандов Э.А. Условнорефлекторное переключение и когнитивная установка // Журнал высшей нервной деятельности им. И.П. Павлова. 2003. № 3. С. 268-278.

28. Костандов Э.А и др. Журнал высшей нервной деятельности им. И.П. Павлова. 2002. № 5. С. 531-538.

29. Шильник Л. Между ушами. Феномены мышления, интуиции и памяти. М.: Энас, 2008. 336 с.

30. Бехтерева Н.П. Здоровый и больной мозг человека. Л.: Наука, 1980. 208 с.

31. Бехтерева Н.П., Гоголицын Ю.Л., Кропотов Ю.Д., Медведев С.В. Нейрофизиологические механизмы мышления. Л.: Наука, 1985. 272 с.

32. Гусев А.Н., Михайлова О.А., Уточкин И.С. Роль индивидуально-психологических свойств личности в выраженности феномена слепоты к изменению // Вопросы психологии. 2012. № 4.

33. Никифоров А.С. Неврология: Полный толковый словарь. М.: Эксмо, 2010. 464 с. 


\section{Психология и психотехника 11(86) • 2015}

34. Блейхер В.М. Расстройства мышления. Киев: Здоровье, 1983. 192 с.

35. Зейгарник Б.В. Патопсихология. М., 2001. 324 с.

36. Зейгарник Б.В. Патология мышления. М., 2000. 459 с.

37. Дунаевский В.В. Психиатрия и психосоматическая медицина. СПб.: Интеграф, 1995. 378 с.

38. Хомская Е.Д. Нейропсихология. СПб.: Питер, 2005. 496 с.

39. Крайг Г. Психология развития. СПб.: Питер, 2000. 375 с.

40. Дубровинская Н.В. Некоторые характеристики внимания в онтогенезе // Психологический журнал. 1982. № 2. С. 35-40.

41. Гарбузов В.И., Захаров А.И., Исаев Д.Н. Неврозы у детей и их лечение. М.: Медицина, 1977. 272 с. С. 14-24.

42. Захаров А.И. Неврозы у детей и психотерапия. СПб., 1998. 336 с.

43. Захаров А.И. Психотерапия неврозов у детей подростков. М., 1982.

44. Спиваковская А.С. Профилактика детских неврозов. М., 1988. 273 с.

45. Столин В.В. Самосознание личности. М., 1983.

46. Личко А.Е. Подростковая психиатрия. М.: Медицина, 1985. 416 с.

47. Эйдемиллер Э.Г. Методы семейной диагностики и психотерапии. М.; СПб., 1996. 365 с.

48. Adler Alfred. Problems of neurosis. New York, 1930. 73 p.

49. Варга А.Я. Роль родительского отношения в стабилизации детской невротической реакции (на примере энуреза) // Вестник МГУ. Психология. 1985. № 4.

50. Козловская Г.В. Нарушения психического развития у детей раннего возраста в условиях шизофреногенной семьи // Социокогнитивное развитие ребёнка в раннем детстве. М., 1995. 214 с.

51. Гребенников И.В. Воспитательный климат семьи. М.: Знание, 1976. 40 с.

52. Обухова Л.Ф. Детская психология: теории, факты, проблемы. М., 1995. 360 с.

53. Х Хоментаускас Г.Т. Семья глазами ребёнка. М.: Педагогика, 1989. 160 с.

54. Овчинникова Т.Н. Личность и мышление ребёнка. М.: Академический проект, 2004. 192 с.

55. Рубинштейн С.Л. О мышлении и путях его исследования. М.: Изд-во Академии наук СССР, 1958. 142 с.

56. Выготский Л.С. Мышление и речь // Выготский Л.С. Психология. М.: ЭКСМО-Пресс, 2002. 1008 с.

57. Пиаже Ж. Психология интеллекта / Пер с фр. СПб.: Питер, 2004. 192 с. (Серия «Психология-классика»)

58. Эйдемиллер Э.Г., Юстицкий В.В. Анализ семейных отношений подростков при психопатиях, акцентуациях характера, неврозах и неврозных состояниях. М., 1994.96 с.

59. Эйдемиллер Э.Г., Юстицкис В.В. Психология и психотерапия семьи. СПб.: Питер, 1999. 656 с.

60. Денисенкова Н.С. Влияние семьи на развитие способностей ребёнка // Современное дошкольное образование. Теория и практика. 2012. № 2. С. 60-65.

61. Гиляровский В.А. Психиатрия: Руководство для врачей и студентов. 4-е изд., испр. и доп. М.: Медгиз, 1954.520 с.

62. Залевский Г.В. Фиксированные формы поведения индивидуальных и групповых систем (в культуре, образовании, науке и патологии). М.; Томск: Томский государственный университет, 2004. 460 с.

63. Староверова М.С. Неуспешность в обучении: природные и социальные факторы и пути коррекции // Директор школы. 2002. № 4. С. 42-45.

64. Репина Н.В., Воронцов Д.В., Юматова И.И. Основы клинической психологии. М.: Феникс, 2003. 480 с.

65. Марютина Т.М., Ермолаев О.Ю. Введение в психофизиологию. М.: МПСИ; Флинта, 2001. 400 с.

\section{References (transliteration):}

1. Gordynya N.D. Issledovanie rigidnosti-gibkosti poznavatel'nogo kontrolya i impul'sivnosti-reflektivnosti u studentovaviadispetcherov. // «Molodoi uchenyi». 2013. № 5. S. 634-638.

2. Zalevskii G.V. Psikhicheskaya rigidnost' v norme i patologii. Tomsk: Izd-vo Tomskogo universiteta, 1993. $272 \mathrm{s.}$

3. Kholodnaya M.A. Psikhologiya intellekta: paradoksy issledovaniya. 2-oe izd., pererab. i dop. SPb.: Piter, 2002.272 s.

4. Leifrid N.V. Otvetstvennost' kak lichnostnaya determinanta predstavlenii ob uspeshnom cheloveke: Dis. ... kand. psikhol. nauk. Krasnodar, 2006. 220 s.

5. Zinchenko V.P., Meshcheryakova B.G. Psikhologicheskii slovar'. M.: Pedagogika-press, 1996. 367 s.

6. Tvorogov N.D. Klinicheskaya psikhologiya. M.: PER SE, 2007. $416 \mathrm{s.}$

7. Bleikher V.M., Kruk I.V., Bokov S.N. Klinicheskaya patopsikhologiya. Voronezh: NPO «MODEK», 2002. $512 \mathrm{~s}$.

8. Norakidze V.G. Temperament lichnosti i fiksirovannaya ustanovka // Eksperimental'nye issledovaniya po psikhologii ustanovki. T. 1. Tbilisi: Izd-vo AN GSSR, 1958. 348 s.

9. Cowen E.L. The influence of varying degrees of psychological stress on problem-solving rigidity // J. of Abn. and Soc. Psychol. 1952. N. 47. P. 512-529.

10. Luchins A.S., Luchins E.H. Wertheimer's seminars revisited. Problem-solving and thinking. V. 3. Albany, 1970. 439 p.

11. Dunker K. Psikhologiya produktivnogo (tvorcheskogo) myshleniya // Psikhologiya myshleniya: Sb. perevodov s nem. i angl. / Pod red. A.M. Matyushkina. M.: Progress, 1965. S. 199-221.

12. Uznadze D.N. Eksperimental'nye osnovy psikhologii ustanovki // Eksperimental'nye issledovaniya po psikhologii ustanovki / Red. A.S. Prangishvili, Z.I. Khodzhava. Tbilisi: Izd-vo Gruzinskoi AN, 1958. S. 5-126.

13. Kolb \& Whishaw: Fundamentals of Human Neuropsychology. 2003. P. 453-454, 457.

14. Burmistrova E.V., Maksutova N.G. Kognitivnye i lichnostnye osobennosti operatorov svyazi sluzhb ekstrennogo reagirovaniya // Materialy I Mezhdunarodnogo foruma «Psikhologicheskaya bezopasnost', ustoichivost', psikhotravma» (SPb. 5-7 iyunya 2006 g.) / Pod red. I.A. Baevoi, Sh. Ionesku, L.A. Regush, S.A. Chernyshevoi. SPb.: Knizhnyi dom, 2006. 214 s.

15. Ivanova E.M. Psikhologiya professional'noi deyatel'nosti. M.: Kogito-tsentr, 2011. $336 \mathrm{~s}$. 
16. Maksutova N.G. Problemy podgotovki operatorov svyazi informatsionnykh tsentrov sluzhb spaseniya // Materialy nauchnoprakticheskoi konferentsii «Problemy psikhologii XXI veka glazami molodykh uchenykh». M.: Izd. tsentr «ELLARADA», 2002. S. 85-87.

17. Volkov E.N. Osnovnye modeli kontrolya soznaniya (reformirovaniya myshleniya) // Zhurnal prakticheskogo psikhologa. 1996. № 5.

18. Brushlinskii A.V. Sub"ekt: myshlenie, uchenie, voobrazhenie. M.: MPSI; Voronezh: MODEK, 2003. $398 \mathrm{s.}$

19. Shadrikov V.D. Psikhologiya deyatel'nosti i sposobnosti cheloveka. M.: Logos, 1996. 320 s. S. 198-222.

20. Ryzhov B.N. Sistemnaya psikhologiya. Metodologiya i metody psikhologicheskogo issledovaniya. M.: MGPU, 1999.277 s. S. 139-175.

21. Romanova E.S., Reshetina S.Yu. Professional'naya orientatsiya s pozitsii kontseptsii samodiagnostiki // Prikladnaya psikhologiya. 2001. № 3. S. 19-40.

22. Kostandov E.A. Psikhofiziologiya soznaniya i bessoznatel'nogo. SPb.: Piter, 2004. 176 s.

23. Cattell R.B. The scientific analysis of personality. Baltimore Praeger, 1965.

24. Nizharadze G.A. Vliyanie motivatsionnykh faktorov na rigidnoe povedenie: Dis. ... kand. psikhol. nauk. Tbilisi, $1984.132 \mathrm{~s}$.

25. Nizharadze G.A. O dvukh tipakh rigidnosti pri reshenii intellektual'nykh zadach // Voprosy psikhologii. 1987. № 3. S. 142-145.

26. Kurova N.S., Cheremushkin E.A., Ashkinazi M.L. Kogerentnost' EEG pri deistvii neosoznavaemoi zritel'noi ustanovki v usloviyakh povyshennoi motivatsii ispytuemykh // Zhurnal vysshei nervnoi deyatel'nosti im. I.P. Pavlova. 2003. № 6. S. 705-711.

27. Kostandov E.A. Uslovnoreflektornoe pereklyuchenie i kognitivnaya ustanovka // Zhurnal vysshei nervnoi deyatel'nosti im. I.P. Pavlova. 2003. № 3. S. 268-278.

28. Kostandov E.A i dr. Zhurnal vysshei nervnoi deyatel'nosti im. I.P. Pavlova. 2002. № 5. S. 531-538.

29. Shil'nik L., Mezhdu ushami. Fenomeny myshleniya, intuitsii i pamyati. M.: Enas, 2008. $336 \mathrm{~s}$.

30. Bekhtereva N.P. Zdorovyi i bol'noi mozg cheloveka. L.: Nauka, 1980. 208 s.

31. Bekhtereva N.P., Gogolitsyn Yu.L., Kropotov Yu.D., Medvedev S.V. Neirofiziologicheskie mekhanizmy myshleniya. L.: Nauka, 1985. $272 \mathrm{~s}$.

32. Gusev A.N., Mikhailova O.A., Utochkin I.S. Rol' individual'no-psikhologicheskikh svoistv lichnosti v vyrazhennosti fenomena slepoty k izmeneniyu // Voprosy psikhologii. 2012. № 4.

33. Nikiforov A.S. Nevrologiya. Polnyi tolkovyi slovar'. M.: Eksmo, 2010. $464 \mathrm{~s}$.

34. Bleikher V.M. Rasstroistva myshleniya. Kiev: Zdorov'e, 1983. $192 \mathrm{s.}$

35. Zeigarnik B.V. Patopsikhologiya. M., 2001. 324 s.

36. Zeigarnik B.V. Patologiya myshleniya. M., 2000. $459 \mathrm{s.}$

37. Dunaevskii V.V. Psikhiatriya i psikhosomaticheskaya meditsina. SPb.: Integraf, 1995. 378 s.

38. Khomskaya E.D. Neiropsikhologiya. SPb.: Piter, 2005. 496 s.

39. Kraig G. Psikhologiya razvitiya. SPb.: Piter, 2000. 375 s.

40. Dubrovinskaya N.V. Nekotorye kharakteristiki vnimaniya v ontogeneze // Psikhologicheskii zhurnal. 1982. № 2. S. 35-40.

41. Garbuzov V.I., Zakharov A.I., Isaev D.N. Nevrozy u detei i ikh lechenie. M.: Meditsina, 1977. 272 s. S. 14-24.

42. Zakharov A.I. Nevrozy u detei i psikhoterapiya. SPb., 1998. $336 \mathrm{s.}$

43. Zakharov A.I. Psikhoterapiya nevrozov u detei podrostkov. M., 1982.

44. Spivakovskaya A.S. Profilaktika detskikh nevrozov. M., 1988. 273 s.

45. Stolin V.V. Samosoznanie lichnosti. M., 1983.

46. Lichko A.E. Podrostkovaya psikhiatriya. M.: Meditsina, 1985. $416 \mathrm{s.}$

47. Eidemiller E.G. Metody semeinoi diagnostiki i psikhoterapii. M.; SPb., 1996. 365 s.

48. Adler Alfred. Problems of neurosis. New York, 1930. 73 p.

49. Varga A.Ya. Rol' roditel'skogo otnosheniya v stabilizatsii detskoi nevroticheskoi reaktsii (na primere enureza) // Vestnik MGU. Psikhologiya. 1985. № 4.

50. Kozlovskaya G.V. Narusheniya psikhicheskogo razvitiya u detei rannego vozrasta v usloviyakh shizofrenogennoi sem'i // Sotsiokognitivnoe razvitie rebenka v rannem detstve. M., 1995. $214 \mathrm{~s}$.

51. Grebennikov I.V. Vospitatel'nyi klimat sem'i. M.: Znanie, 1976. 40 s.

52. Obukhova L.F. Detskaya psikhologiya: teorii, fakty, problemy. M., 1995. $360 \mathrm{~s}$.

53. Khomentauskas G.T. Sem'ya glazami rebenka. M.: Pedagogika, 1989. 160 s.

54. Ovchinnikova T.N. Lichnost' i myshlenie rebenka. M.: Akademicheskii proekt, 2004. $192 \mathrm{~s}$.

55. Rubinshtein S.L. O myshlenii i putyakh ego issledovaniya. M.: Izd-vo Akademii nauk SSSR, 1958. $142 \mathrm{s.}$

56. Vygotskii L.S. Myshlenie i rech' // Vygotskii L.S. Psikhologiya. M.: EKSMO-Press, 2002. 1008 s.

57. Piazhe Zh. Psikhologiya intellekta / Per s fr. SPb.: Piter, 2004. 192 s. (Seriya «Psikhologiya-klassika»)

58. Eidemiller E.G., Yustitskii V.V. Analiz semeinykh otnoshenii podrostkov pri psikhopatiyakh, aktsentuatsiyakh kharaktera, nevrozakh i nevroznykh sostoyaniyakh. M., 1994. 96 s.

59. Eidemiller E.G., Yustitskis V. Psikhologiya i psikhoterapiya sem'i. SPb.: Piter, 1999. $656 \mathrm{~s}$.

60. Denisenkova N.S. Vliyanie sem'i na razvitie sposobnostei rebenka // Sovremennoe doshkol'noe obrazovanie. Teoriya i praktika. 2012. № 2. S. 60-65.

61. Gilyarovskii V.A. Psikhiatriya: Rukovodstvo dlya vrachei i studentov. 4-e izd., ispr. i dop. M.: Medgiz, 1954.520 s.

62. Zalevskii G.V. Fiksirovannye formy povedeniya individual'nykh i gruppovykh sistem (v kul'ture, obrazovanii, nauke i patologii). M.; Tomsk: Tomskii gosudarstvennyi universitet, 2004. $460 \mathrm{~s}$.

63. Staroverova M.S. Neuspeshnost’ v obuchenii: prirodnye i sotsial’nye faktory i puti korrektsii // Direktor shkoly. 2002. № 4. S. 42-45.

64. Repina N.V., Vorontsov D.V., Yumatova I.I. Osnovy klinicheskoi psikhologii. M.: Feniks, 2003. 480 s.

65. Maryutina T.M., Ermolaev O.Yu. Vvedenie v psikhofiziologiyu. M.: MPSI; Flinta, 2001. 400 s. 